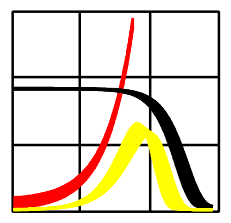

Max-Planck-Institut für demografische Forschung

Max Planck Institute for Demographic Research

Doberaner Strasse 114 - D-18057 Rostock - GERMANY

Tel +49 (0) 3812081 - 0; Fax +49 (0) 3812081 - 202;

http://www.demogr.mpg.de

MPIDR WORKING PAPER WP 2000-002

FEBRUARY 2000 (Revised 5 October 2000)

\title{
Agricultural productivity growth and escape from the Malthusian trap
}

Tomas Kögel (Koegel@ demogr.mpg.de)

Alexia Prskawetz (Fuernkranz@demogr.mpg.de)

C Copyright is held by the authors.

Working papers of the Max Planck Institute for Demographic Research receive only limited review. Views or opinions expressed in working papers are attributable to the authors and do not necessarily reflect those of the Institute. 


\title{
Agricultural productivity growth and escape from the Malthusian trap
}

\author{
Tomas Kögel *and Alexia Prskawetz \\ Max Planck Institute for Demographic Research \\ Doberanerstr. 114, 18057 Rostock, Germany
}

October 5, 2000

\begin{abstract}
Industrialization allowed the industrialized world of today to escape from a regime characterized by low economic and population growth and to enter a regime of high economic and population growth. To explain this transition of regimes, we construct a two-sector growth model with endogenous fertility and endogenous technological progress in the manufacturing sector. With this structure our model is able to replicate the stylized facts of the British industrial revolution. In addition, we show that industrialization requires rising growth of agricultural total factor productivity. This result is in marked contrast to previous work within a similar framework - but with a constant population - which came to the conclusion that industrialization requires merely a rising level of agricultural total factor productivity. We conclude by illustrating that our proposed model framework can be extended to also include the demographic transition, i.e., a regime where economic growth may lead to decreasing fertility.
\end{abstract}

(JEL-code: J13, O11, O40. Keywords: Fertility choice, economic growth, Malthusian trap, technological change.)

*Corresponding author: Fax: 0049-(0)-381-2081-446, phone: 0049-(0)-381-2081-146, email: Koegel@demogr.mpg.de. The authors are grateful for comments and suggestions from Oded Galor, two anonymous referees, Tim Hatton, and participants at workshops at Zurich and Harvard and at the ESPE 2000 conference in Bonn. The views expressed in this paper are the authors' own views and do not necessarily represent those of the Max Planck Institute for Demographic Research. 


\section{Introduction}

In his classical work Malthus (1798) argued that any increase in agricultural productivity would result in population growth, but not in long-run per capita income growth. The underlying assumptions are twofold. First, any increase of per capita income above a particular equilibrium level of consumption leads to population growth. Second, Malthus believed that population growth dilutes per capita resources and, as a consequence, consumption should fall back to its equilibrium level. As a result, any economy will be trapped in a situation where no sustained growth of per capita income can occur. This trap is commonly labeled Malthusian trap or low level equilibrium trap (see Nelson, 1956).

Malthus' view correctly describes the demography and economy of Western Europe before and during his lifetime, which was the eighteenth century. Until this time there had been slow population growth, low per capita income growth and population growth had a negative effect on per capita income growth. However, the industrial revolution later launched Western Europe into a new phase of human history, in which population growth ceased to prevent long-run growth of per capita income. One can refer to this new stage as the take-off into self-sustained growth (see Rostow, 1960). ${ }^{1}$ Moreover, population growth accelerated (see Maddison, 1991). We label this simultaneous take-off in economic growth and population growth as escape from the Malthusian trap.

While the neoclassical growth model or various endogenous growth models are appropriate for explaining the regime of modern growth, they are inappropriate when it comes to explaining the escape from the Malthusian trap. ${ }^{2}$ For this reason, a recent strand in the growth literature calls on researchers to place more effort to modeling the escape from the Malthusian trap and, more generally, aims explaining economic development ranging from Malthusian stagnation to modern growth within unified models (some advocates of this research program are, e.g., Galor and Weil, 1999 and Lucas,

\footnotetext{
${ }^{1}$ In Great Britain the industrial revolution took place at the end of the eighteenth century. In other Western European countries the industrial revolution followed somewhat later.

${ }^{2}$ In the growth literature agreement is still lacking as to whether the neoclassical growth model (augmented with human capital) or various endogenous growth models are better able to explain the regime of modern growth. Obviously, this issue lies outside the scope of our paper.
} 
1998). Our paper aims to contribute to this promising new research field.

Two recent papers devoted to this research topic are Galor and Weil (1998) and Jones (1999a). Galor and Weil and also Jones construct endogenous growth models with endogenous fertility which can replicate all of human history from the Malthusian regime to the present. ${ }^{3}$

Closest to our paper is Hansen and Prescott (1998). Their model has in common with our model the fact that there are two sectors, one sector which uses a technology with decreasing returns to labor (due to presence of land as input factor that is given for the economy in fixed supply) and another sector with non-decreasing returns to labor. While in our model we assume that these two sectors produce different consumption goods, Hansen and Prescott assume that the two sectors represent two different technologies that produce the same consumption good. Total factor productivity for both technologies grows exogenously. For a low level of total factor productivity for the technology with non-decreasing returns to labor only the technology with decreasing returns to labor is profitable and population growth prevents growth of per capita output, i.e., the economy is caught in a Malthusian trap. Once the level of total factor productivity for the technology with nondecreasing returns to labor exceeds a threshold level, this technology becomes profitable, as well. As a consequence, the economy starts the take-off into self-sustained growth and, at the same time, population growth accelerates, i.e, the economy escapes from the Malthusian trap. ${ }^{4}$

In our view there is an important weak point in Hansen and Prescott's model; namely the assumption that both technologies produce the same good (though not named as such, the two technologies represent an agricultural technology and a manufacturing technology, respectively). This means demand factors are neglected. However, economic historians, such as Crafts (1985), identify an important role for demand factors in the industrialization of Western Europe. Crafts shows empirical evidence for income-inelastic demand for agricultural goods in pre-industrialized societies. This evidence implies that per capita income growth leads to labor reallocation towards

\footnotetext{
${ }^{3}$ In addition, Galor and Weil (1996, section 3B) generate a pattern of increasing and then decreasing fertility based on a transition from a traditional to a modern sector. In their set up production in the traditional sector can take place at home and, therefore, can be combined with childrearing. In contrast, work in the modern sector cannot be combined with childrearing.

${ }^{4}$ Another paper that models the effect of population growth on industrialization, however takes population growth to be exogenous, is Goodfriend and McDermott (1995).
} 
the non-agricultural sector. Matsuyama (1992, Section 2) shows in a closedeconomy model with two consumption goods (namely, an agricultural good and a manufacturing good), with an income-inelastic demand for the agricultural good, and a constant population, that an increase in the agricultural total factor productivity level unambiguously leads to a take-off in per capita income growth (henceforth we label agricultural total factor productivity as agricultural TFP) .

While Matsuyama's model incorporates important demand factors, it ignores population growth. We correct this omission by introducing endogenous population growth into his framework (in doing so, we introduce a further demand factor, namely, that increasing income leads to rising demand for children). Our paper demonstrates that augmenting Matsuyama's framework with endogenous population growth implies that a take-off in per capita income growth cannot result from an increase in the agricultural TFP level, only- it requires an increase in agricultural TFP growth.

We endogenize population growth by assuming fertility to be the result of utility maximizing behavior. As a result, fertility rises in the wage rate. This is supported for pre-industrialized societies in important empirical work by Bailey and Chambers (1993) and also in Lee (1997).

Though our model primarily focuses on the transition from the Malthusian regime (i.e., the time before the industrialization) towards the postMalthusian regime our model framework can be extended to also include the demographic transition. While per capita income growth had a positive effect on population growth in the Malthusian and post-Malthusian regime, self-sustained growth was present in the post Malthusian regime, only. During the demographic transition economic growth continued while the relation between income and population growth turned negative.

It should also be mentioned that we ignore for simplicity mortality in our paper (though we do not deny a role for it in reality) and focus exclusively on fertility. ${ }^{5}$ What we have in mind is that parents take infant mortality into consideration and choose fertility net of the probability of their children to die before they reach adulthood. ${ }^{6}$ Our focus on fertility is justified by the

\footnotetext{
${ }^{5}$ On modeling the importance of mortality declines to escape from the Malthusian trap, see Galor and Weil (1999) and Steinmann, Prskawetz and Feichtinger (1998). While Galor and Weil assume increasing returns to investment in human capital accumulation if mortality decreases, Steinmann et al. assume that the rate of depreciation of human capital is decreasing in mortality improvements.

${ }^{6}$ In pre-industrialized societies mortality changes were driven predominantly by changes
} 
empirical evidence presented in Dyson and Murphy (1985) and Coale and Treadway (1986) that Western Europe's take-off into self-sustained economic growth was accompanied by rising fertility in Western Europe up to the second half of the nineteenth century.

A further important contribution of our paper is the modeling of technological progress in the manufacturing sector as an endogenous variable. Following the recent literature in endogenous growth theory, endogenous technological progress increases in the rate of population growth. Our framework ensures that population growth will lead to an increase in labor productivity growth in the manufacturing sector, while it tends to reduce labor productivity growth in the agricultural sector (because this sector has decreasing returns to labor). This feature will end up enabling our model to replicate the stylized facts of the British industrial revolution as summarized in the next section.

\section{Stylized facts of the British industrial rev- olution}

Table 1: Per annum growth rates in Great Britain

\begin{tabular}{|c||c|c|c|c|}
\hline Time interval & $\hat{\Omega}_{A, t}$ & $\hat{N}_{t}$ & $\hat{Y}_{t}-\hat{N}_{t}$ & $\hat{A}_{t}-\hat{N}_{t}$ \\
\hline $1700-60$ & $0.50 \%$ & $0.38 \%$ & $0.31 \%$ & $0.22 \%$ \\
$1820-40$ & $0.90 \%$ & $1.34 \%$ & $1.04 \%$ & $0.04 \%$ \\
\hline
\end{tabular}

Source: Crafts (1985, p.158-160)

An important contribution of our paper is the explanation of the stylized facts of the British industrial revolution. These stylized facts are shown in Table 1. While the literature commonly assumes a one-sector model (see, e.g., Lee, 1988, and Jones, 1999a), it will become clear from the table that the stylized facts can only be replicated in a two-sector model.

Table 1 shows annual growth rates of selected series for the time intervals 1700-60 (i.e., before the British industrial revolution) and 1820-40 (i.e,

in infant mortality. 
after the British industrial revolution). In this table $\hat{\Omega}_{A, t}$ denotes annual agricultural total factor productivity growth, $\hat{N}_{t}$ denotes annual population growth, $\hat{Y}_{t}$ denotes annual aggregate income growth and $\hat{A}_{t}$ denotes annual agricultural production growth. ${ }^{7}$

From the table one can infer the following stylized facts of the British industrial revolution:

(i) Column 1 to 3 show that growth of agricultural TFP, population growth and per capita income growth all increased after the industrial revolution. Hence, the data are consistent with the view that an escape from the Malthusian trap was initialized by an (possible exogenous) increase in agricultural TFP growth.

(ii) Column 4 shows that per capita agricultural production growth did not rise after the industrial revolution (as a matter of fact, it even fell). This is consistent with the view that an increase in agricultural TFP growth had a multiplier effect on population growth, i.e., it caused a more than proportional increase in population growth, while it did not cause such a significant increase in total agricultural production growth.

(iii) Since per capita income growth rose after the industrial revolution (cf. column 3), while per capita agricultural production growth fell (cf. column 4), the take-off in per capita income growth after the industrial revolution must have been due almost entirely to a rise in per capita manufacturing output growth. ${ }^{8}$ This finding is consistent with the view that an increase in agricultural TFP growth also had a multiplier effect on per capita manufacturing output growth, i.e., it caused a more than proportional increase in per capita manufacturing output growth.

The agricultural sector has to be modelled to reflect decreasing returns to labor. This assumption is based on the fact that the economy stagnated before the industrial revolution and the fact that accelerating population growth after the industrial revolution caused per capita agricultural production growth to fall. On the other hand, our discussion of the stylized facts from table 1 concluded that the take-off in per capita output growth was entirely due to per capita manufacturing output growth. It is thus clear

\footnotetext{
${ }^{7}$ Henceforth, a "hat" on top of any variable denotes the growth rate of that variable.

${ }^{8}$ Besides the agricultural sector and the manufacturing sector, there also existed a service sector. However, since labor is in the service provision not only an input factor, but also an "end-product" automatization in the service sector is very difficult (see Baumol, 1967). For this reason, it is unlikely that productivity growth in the service sector will figure prominently in an explanation of the data of Table 1.
} 
that only a two-sector model is capable of matching the stylized facts of the British industrial revolution. Indeed, it will turn out later that, with this structure, our model can replicate all stylized facts (i) to (iii) from table $1 .^{9}$

\section{The model}

Our model structure is very similar to the closed-economy model in Matsuyama (1992), but it introduces presence of endogenous fertility. In addition, we model endogenous technological progress in the manufacturing sector in a way that is consistent with recent developments in the endogenous growth literature that took place after Matsuyama's writing.

\subsection{Households}

We assume there are in each period $N_{t}$ individuals and each individual lives one period..$^{10}$ Births take place at the end of each period. ${ }^{11}$ Each individual

\footnotetext{
${ }^{9}$ According to Crafts (1985) the data for 1800-20 are not reliable. For this reason those data are not included in Table 1. Moreover, the corresponding data for 1760-1800 are not included in Table 1 (1760-1800 is the time period at which the British industrial revolution took place). This time period is characterized by a temporary contraction of agricultural total factor productivity growth and per capita output growth and a temporary fall in real wages (Ciccone (1997) explains this temporary fall in the real wage with relatively faster total factor productivity growth in a more capital intensive industrial production sector than the less capital intensive "cottage" sector). Yet, during that time period population growth continued to increase. Birdsall (1983) explains the latter with the fact that industrialization continued in that time period. In turn, industrialization caused an increase in fertility (despite a falling real wage) because of three reasons: (i) Industrial earning opportunities increased which fostered an increase in marriage rates and also marriages at earlier ages. (ii) Rising demand in the manufacturing sector for children as laborers (which reduced parents' costs of children). (iii) Rising home-based female employment in the manufacturing sector, i.e., female employment of a type that was compatible with child care. Though these explanations support our claim that the manufacturing sector played a dominant role in the escape from the Malthusiuan trap, we abstract in our model from these features. Instead, we concentrate on the long-run positive association of wages and fertility between 1700-60 and 1820-40 (as is supported by work of Wrigley and Schofield, 1981).

${ }^{10}$ We use capital letters to denote aggregate variables and lower-case letters to denote per capita variables (i.e., aggregate variables divided by $N_{t}$ ).

${ }^{11}$ Since each parent dies after one period, it does not derive utility from companionship with its children, but from births. This assumption simplifies our model when it comes to defining per capita values, but leads to no loss of generality.
} 
is endowed with one unit of time, which is divided between labor market participation and births. The unit labor requirement for births is $\beta$ (with $0<\beta<1$ ). The wage rate and the full income of each household are both denoted by $w_{t}$. The full income of an individual is the income it would receive, if it devoted its entire time endowment to labor market participation. Each individual faces the constraint that it has to consume the subsistence level ã of the agricultural good in order to survive. ${ }^{12}$ For a low level of full income this constraint is binding and, as a consequence, each individual must cut back the quantities of its other choice variables below their utility-maximizing levels. Consistent with the empirical evidence in Crafts (1985), we assume the agricultural good to be a necessity (so that the income elasticity of demand is below one). For analytical convenience we assume that in case the constraint is not binding, each household still demands inelastically the same quantity ã. ${ }^{13}$ We normalize the agriculture good price to one.

Each individual derives utility from consumption of a manufacturing good $m_{t}$ and births $b_{t}$, implying its choice variables to be $m_{t}$ and $b_{t}$ (consumption of $\tilde{a}$ does not give utility, but it is necessary for survival). In order to focus our attention on the transition from the Malthusian regime to the postMalthusian regime, which is characterized by the simultaneous increase in per capita income growth and population growth, we assume a Cobb-Douglas utility function, i.e., a utility function with an elasticity of substitution between $m_{t}$ and $b_{t}$ of one. ${ }^{14}$

Given these implicit assumptions each individual's optimization problem at each point in time is

$$
\max u_{t}=m_{t}^{1-\alpha} b_{t}^{\alpha}
$$

\footnotetext{
${ }^{12}$ See similar in Galor and Weil (1998).

${ }^{13}$ As long, as the income elasticity of demand for the agricultural good remains below one, all our results apply in a more general framework.

${ }^{14}$ In section 4 we assumes the elasticity of substitution between $m_{t}$ and $b_{t}$ to be greater than one (see also Jones, 1999a). With that assumption we will be able to explain the demographic transition that followed the post-Malthusian regime (the demographic transition is a situation in which growing per capita income growth started to cause falling population growth). In this section we refrain from that task since our primary focus is to model the escape from the Malthusian trap as it is compatible with the stylized facts of the British industrial revolution.
} 


$$
\begin{array}{r}
\text { s.t. } a_{t}+p_{M, t} m_{t}+w_{t} \beta b_{t}=w_{t}, \\
a_{t} \geq \tilde{a}, m_{t} \geq 0, b_{t} \geq 0,
\end{array}
$$

with $0<\alpha<1$ and $p_{M, t}$ denoting the price of the manufacturing good.

From the Karush-Kuhn-Tucker conditions for optimizing (1) we have

$$
\begin{aligned}
a & =\tilde{a} \\
m_{t} & =(1-\alpha)\left(\frac{1}{p_{M, t}}\right)\left(w_{t}-\tilde{a}\right), \\
b_{t} & =\left(\frac{\alpha}{\beta}\right)\left(1-\frac{\tilde{a}}{w_{t}}\right) .
\end{aligned}
$$

\subsection{The production of the agricultural good}

The market for the agricultural good is perfectly competitive. Production of the agricultural good $A_{t}$ requires labor $L_{A, t}$ and land $T$ as input factors. We abstract in the entire paper from capital without loss of generality. In agricultural production there are constant returns to scale in $L_{A, t}$ and $T$ together. Land is given for the economy in fixed quantity. This implies that for any given level of agricultural TFP $\Omega_{A, t}$ there are decreasing returns to labor in the production of the agricultural good. We assume the aggregate agricultural production function to have a Cobb-Douglas-form.

Given these implicit assumptions the aggregate agriculture production function is

$$
A_{t}=\Omega_{A, t} L_{A, t}^{\gamma} T^{1-\gamma}=\Omega_{A, t} L_{A, t}^{\gamma}, \text { with } T \equiv 1,
$$

where $0<\gamma<1$.

If labor in the agricultural sector were paid according to its factor productivity, presence of decreasing returns to labor would imply positive profits for farmers. In order to avoid complication from positive profits, we make the following Assumption 1 which seems realistic for primitive societies. ${ }^{15}$

\footnotetext{
${ }^{15}$ This assumption is borrowed from an earlier version of Jones (1999a).
} 
ASSUMPTION 1: Wage payment in the agricultural sector occurs according to the rule

$$
w_{t}=\frac{A_{t}}{L_{A, t}}=\Omega_{A, t} L_{A, t}^{\gamma-1} .
$$

In each period there are $N_{t}$ households which demand $N_{t} \tilde{a}$ units of the agricultural good. Setting demand equal to supply gives the equilibrium level of labor in the agricultural sector as $L_{A, t}=\left(\frac{N_{t} \tilde{a}}{\Omega_{A, t}}\right)^{\frac{1}{\gamma}}$. Substituting the equilibrium level of $L_{A, t}$ back into the definition of the wage payment in Assumption 1 results in an equilibrium wage of

$$
w_{t}=\left(N_{t} \tilde{a}\right)^{\frac{\gamma-1}{\gamma}} \Omega_{A, t}^{\frac{1}{\gamma}} .
$$

For clarification, we state the following definition which is based on a related framework in Galor and Weil (1998):

\section{DEFINITION:}

(i) We define a Malthusian steady state as a situation in which the population and per capita manufacturing output grow at the rate zero.

(ii) We define a post-Malthusian balanced growth path as a situation in which the population and per capita manufacturing output grow at constant, positive rates.

In addition, we introduce Assumption 2 (i) to ensure $w_{0} \geq \tilde{a}$ for $\mathrm{t}=0$ (this condition can be derived from imposing in (7) that $w_{0}=\left(N_{0} \tilde{a}\right)^{\frac{\gamma-1}{\gamma}} \Omega_{A, 0}^{\frac{1}{\gamma}}$ $\geq \tilde{a}$ and collecting terms). Appendix B shows the further Assumption 2 (ii) to guarantee together with Assumption 2 (i) fulfillment of the household constraint $a_{t}=\tilde{a}, \forall t$.

\section{ASSUMPTION 2:}

(i) $N_{0} \leq\left(\frac{\Omega_{A, 0}}{\tilde{a}}\right)^{\frac{1}{1-\gamma}}$,

(ii) $1-\gamma \leq\left(\frac{\beta}{\alpha}\right)\left(\hat{\Omega}_{A, t}+1\right)^{\frac{1}{1-\gamma}}<1$. 


\subsection{The production of the manufacturing good}

Following Ethier (1982) we assume the final manufacturing good to be produced by assembling a very large number of varieties of a horizontally differentiated intermediate good which are supplied in monopolistically competitive markets. The aggregate production function is assumed to have the form $^{16}$

$$
M_{t}=\left(\int_{0}^{Q_{t}} X_{i, t}^{\frac{\varepsilon-1}{\varepsilon}} d i\right)^{\frac{\varepsilon}{\varepsilon-1}}, \varepsilon>1
$$

where $M_{t}$ denotes aggregate final manufacturing good production, $Q_{t}$ denotes the number of varieties of the intermediate good, $X_{i, t}$ denotes the quantity of the intermediate good variety $i$ and $\varepsilon$ denotes the elasticity of substitution between varieties of the intermediate good. As we will later see, in the case where $\varepsilon>1$, eq. (8) implies that there is productivity gain from increasing diversity of intermediate goods varieties. ${ }^{17}$ Perfect competition in the market for the final manufacturing good causes the final manufacturing good price $p_{M, t}$ to equal the final manufacturing good unit cost. Therefore, upon cost minimization $p_{M, t}$ is derived as

$$
p_{M, t}=\left(\int_{0}^{Q_{t}} p_{X_{i, t}}^{1-\varepsilon} d i\right)^{\frac{1}{1-\varepsilon}}
$$

where $p_{X_{i}, t}$ represents the price of the intermediate goods variety i. Profit maximization of final manufacturing goods firms gives rise to the following aggregate demand for each intermediate goods variety $\mathrm{i}$

$$
X_{i, t}=\left(\frac{p_{M, t}}{p_{X_{i, t}}}\right)^{\varepsilon} M_{t}
$$

\footnotetext{
${ }^{16}$ Goodfriend and Dermott (1998) assume a similar production function for the industrial revolution. In a model of modern growth Young (1998) enlarges the above production function with endogenous quality improvements and vertical knowledge spillovers. While Young's framework is richer, we use the simpler framework as given by (8) in order to focus attention on the interactions between population growth and economic growth. As was already noted in Ethier (1982), one could alternatively interpret the intermediate goods varieties as successive stages and such an interpretation would leave the implications of the model unaffected (see Edwards and Starr, 1987, for a formalization of this interpretation).

${ }^{17}$ It will later be shown that $\varepsilon>1$ is an additional necessary condition for intermediate goods firms to be willing to engage in production.
} 
We assume that the total labor requirement of each intermediate goods firm for producing $X_{i, t}$ units equals $L_{X_{i, t}}$, with $L_{X_{i, t}}=F+\delta X_{i, t}$, where $\mathrm{F}$ denotes each intermediate goods firms' fixed cost, which is due each period, and $\delta$ represents its unit labor requirement. Solving (10) for $p_{X_{i}, t}$, substituting the resulting expression in the profit definition for each intermediate goods firm i, $\Pi_{i, t}=p_{X_{i, t}} X_{i, t}-w_{t}\left(F+\delta X_{i, t}\right)$ and maximizing $\Pi_{i, t}$ by optimal choice of $X_{i, t}$ yields the well-known monopoly-pricing rule ${ }^{18}$

$$
p_{X_{i, t}}\left(1-\frac{1}{\varepsilon}\right)=w_{t} \delta \quad \text { or } \quad p_{X_{i, t}}=p_{\bar{X}_{t}}=\left(\frac{\varepsilon}{\varepsilon-1}\right) w_{t} \delta, \forall i \in\left[0, Q_{t}\right]
$$

where $p_{\bar{X}_{t}}$ denotes the price of each intermediate goods variety. ${ }^{19}$ Note that due to free labor mobility between agricultural goods producers and intermediate goods firms the wage rate is the same in both sectors and determined in the agricultural good sector according to (7). In addition, there is free entry into the market for each intermediate goods variety until for each intermediate goods firm a zero-profit condition is fulfilled. Substituting (11) in the profit definition of each intermediate goods firm and setting $\Pi_{i, t}=0$ we obtain

$$
X_{i, t}=\bar{X}=\frac{(\varepsilon-1) F}{\delta}, \forall i \in\left[0, Q_{t}\right]
$$

Equation (12) establishes that only a constant output level of each intermediate goods variety is consistent with zero profit and, due to symmetry, that this output level is the same for each intermediate goods variety. Utilizing this fact in (8) yields

\footnotetext{
${ }^{18}$ Due to product differentiation, each intermediate goods firm enjoys monopoly power in the production of its respective variety. As a consequence, it realizes that its choice of $X_{i, t}$ influences $p_{X_{i}, t}$. Nevertheless, it takes $p_{M, t}, M_{t}$ and $w_{t}$ as given because it believes that it is too small to have any influence on these variables.

${ }^{19}$ While in the production function of the manufacturing good in (8) $\varepsilon$ represents the elasticity of substitution between intermediate goods varieties, in the pricing rule in (11) it represents the price elasticity of demand for each intermediate goods variety. Helpman and Krugman (1985, Ch.6) derived that for a large number of intermediate goods varieties the elasticity of substitution approaches the price elasticity. In the first equation in the pricing rule (11) the left hand side represents marginal revenue and the right hand side represents marginal cost. As a consequence, our assumption $\varepsilon>1$, which we made in (8), ensures positive marginal revenues of monopoly intermediate goods producers.
} 


$$
M_{t}=Q_{t}^{\frac{\varepsilon}{\varepsilon-1}} \bar{X}=Q_{t}^{\frac{1}{\varepsilon-1}}\left(Q_{t} \bar{X}\right)
$$

Obviously, we have $Q_{t}(F+\delta \bar{X})=L_{X, t}$, where $L_{X, t}$ represents aggregate intermediate goods employment. Rewriting this identity and substituting (12) for $\bar{X}$ gives

$$
Q_{t}=\left(\frac{1}{\varepsilon F}\right) L_{X, t}
$$

Substitution of (12) and (14) in (13) yields:

$$
M_{t}=\Omega_{M, t} L_{X, t}, \text { with } \Omega_{M, t} \equiv\left[\varepsilon^{\frac{\varepsilon}{1-\varepsilon}} F^{\frac{1}{1-\varepsilon}}\left(\frac{\varepsilon-1}{\delta}\right)\right] L_{X, t}^{\frac{1}{\varepsilon-1}}
$$

where $\Omega_{M, t}$ denotes manufacturing productivity.

It follows from (15) that the growth rate of manufacturing productivity is independent of the level of $L_{X, t}$, but is increasing in the growth rate of $L_{X, t}$. It will later be shown that the level of $L_{X, t}$ rises in the population level. Therefore, (15) has two implications for manufacturing productivity growth: (i) It is independent of the population level and (ii) it is increasing in the population growth rate. Implication (i) is compatible with the recent credo to be found in the largest part of the endogenous growth literature stating that economic growth models ought to imply a lack of scale effects (i.e., the balanced growth rate of per capita output should be independent of the population level). This credo goes back to Jones (1995a and 1995b) who rejects economic growth with scale effects empirically. Furthermore, all growth models with endogenous technological progress and a lack of scale effects, such as, e.g., Jones (1995b), imply the balanced growth rate of per capita output to be increasing in the population growth rate. As such, our model implication (ii) is compatible with models such as Jones (1995b). In addition our model is also empirically supported, since Kremer (1993) finds 
human historical data from one million B.C. to 1990 to be consistent with models such as Jones (1995b). ${ }^{20}$

To complete the picture, we have to state that the economy is closed. Further, by applying Walras law, it follows that commodity markets clearing implies fullfilment of the country's labor constraint $L_{A, t}+L_{X, t}=N_{t}\left(1-\beta b_{t}\right)$.

\subsection{Results}

To clarify the dynamic properties of the model it is useful to state the following proposition: ${ }^{21}$

PROPOSITION: Suppose total factor productivity in the agricultural good production $\Omega_{A, t}$ grows exogenously at the constant rate $\hat{\Omega}_{A}$ (which is possibly zero). Then, we have a Malthusian steady state or post-Malthusian balanced growth path with:

(i)

$$
\begin{gathered}
w=\text { const. } \\
\hat{N}=\left(\hat{\Omega}_{A}+1\right)^{\frac{1}{1-\gamma}}-1=\text { const. } \\
\frac{L_{X}}{N}=\text { const. }
\end{gathered}
$$

\footnotetext{
${ }^{20} \mathrm{As}$ is argued in Jones (1999b), there are two classes of non-scale economic growth models. The first class of these models (henceforth labeled semi-endogenous growth models) implies that economic growth cannot be sustained in the long run if population growth is absent (models belonging to this class are Jones, 1995a, and Segerstrom, 1998). In the second class of these models (henceforth labeled endogenous growth models), economic growth can be sustained in the long run even if population growth is absent (models belonging to this class are Young, 1998, and Aghion and Howitt, 1998, Ch. 12). Our model belongs to the class of semi-endogenous growth models. Li (2000) shows that any non-scale growth model belongs to the class of semi-endogenous growth models unless two very restrictive knife-edge conditions are fullfiled. In the latter case the model becomes a member of the class of endogenous growth models. Hence, semi-endogenous growth models, such as our model, seem to be more realistic due to their generality,.

${ }^{21}$ Whether we have a Malthusian steady state or post-Malthusian balanced growth path will later turn out to depend on whether we assume $\hat{\Omega}_{A}$ to equal zero or to have a positive value. For the moment, we leave this assumption unspecified.
} 
(i.e., a stationary wage rate, a constant population growth rate and a constant share of aggregate intermediate good employment in the population level).

(ii) Stability of the stationary state of $w$ is guaranteed by Assumption 2 (ii).

PROOF: See Appendix A.

The reader should note that the existence of a steady state or balanced growth path requires a constant share of intermediate goods employment in the population, as well as a constant number of births. In addition, $\mathrm{w}=$ const. does not necessarily imply a constant level of per capita income deflated by a cost-of-living index (see also Appendix C) due to the fact that in the balanced growth path $p_{M, t}$ falls over time.

Now we are prepared to state the following Theorem 1 and Corollary 1:

THEOREM 1: If total factor productivity in agricultural good production $\Omega_{A, t}$ grows at the rate zero, there exists a Malthusian steady state with a constant population level $N^{*}$ and a constant per capita level of manufacturing output $m^{*}$.

PROOF: Let us denote the Malthusian steady state value of any variable with the superscript ${ }^{*}$. Substituting $\hat{\Omega}_{A}=0$ in (17) gives $\hat{N}^{*}=0$. Combining the latter with (18) gives rise to $L_{X}^{*}=$ const. However, as can be seen from (15), $L_{X}^{*}=$ const. together with $\hat{N}^{*}=0$ implies

$$
\hat{m}^{*}=0
$$

COROLLARY 1: Theorem 1 implies that an exogenous increase in the level of $\Omega_{A}$ has no effect on the Malthusian steady state values of $\hat{N}^{*}$ and $\hat{m}^{*}$. For this reason, this level change neither causes permanent population growth, nor does it cause permanent per capita manufacturing output growth.

Though our model framework is very similar to the closed economy framework in Matsuyama (1992) — with the important exception that there the population level is assumed to be constant - our result stated in Corollary 1 is in sharp contrast to that of Matsuyama. There, an exogenous increase in $\Omega_{A}$ increases the wage rate. Since there is income-inelastic demand for the 
agricultural good, the wage increase leads to labor reallocation towards the manufacturing sector, which is the only sector with productivity growth. As a consequence, the growth rate of a composite consumption index (consisting of the agricultural good and the manufacturing good) rises.

What is the explanation for the different result of our model and that of Matsuyama's model? In our model an increase in $\Omega_{A, t}$ leads to a temporary increase in the wage rate. However, since fertility is rising in income, the temporary increase in the wage rate leads to temporary population growth. Due to decreasing returns to labor in agricultural good production, temporary population growth causes the wage rate to return back gradually to its Malthusian steady state value. As a consequence, population growth gradually peters out. Since according to (18) $\frac{L_{X, t}}{N}$ is stationary in the Malthusian steady state, the stationarity of the population level in the Malthusian steady state implies in this situation that $L_{X, t}$ is stationary, as well. Hence, because according to the definition of $\Omega_{M, t}$ in (15) the value of $\Omega_{M, t}$ is constant for constant $L_{X, t}$ and because by definition $m_{t}=\Omega_{M, t}\left(\frac{L_{X, t}}{N_{+}}\right)$, the per capita level of manufacturing output must be constant in the Malthusian steady state.

The fact that an escape from the Malthusian trap is possible in our model can be seen from the following Theorem 2 and Corollary 2:

THEOREM 2: If total factor productivity in agricultural good production $\Omega_{A, t}$ grows exogenously at the constant, positive rate $\hat{\Omega}_{A}$, there exists a post-Malthusian balanced growth path with:

(i) A constant population growth rate $\hat{N}^{* *}$ and a constant growth rate of per capita manufacturing output $\hat{m}^{* *}$.

(ii) $\hat{N}^{* *}$ and $\hat{m}^{* *}$ are all dependent on the growth rate $\hat{\Omega}_{A}$, with the presence of multiplier effects from an increase of $\hat{\Omega}_{A}$ on $\hat{N}^{* *}$ and $\hat{m}^{* *}$ (the latter provided $\left.\left(\frac{1 /(\varepsilon-1)}{1-\gamma}\right)>1\right)$.

PROOF: Let us denote the value of any variable in the post-Malthusian balanced growth path with the superscript **. The assumption $\hat{\Omega}_{A}>0$ and equation (17) imply

$$
\hat{N}^{* *}=\left(\hat{\Omega}_{A}+1\right)^{\frac{1}{1-\gamma}}-1>0 \text { and } \partial \hat{N}^{* *} / \partial \hat{\Omega}_{A}>0 .
$$

Combining (19) with (18) we obtain

$$
\hat{L}_{X}^{* *}=\hat{N}^{* *}>0 \text { and } \partial \hat{L}_{X}^{* *} / \partial \hat{\Omega}_{A}>0 .
$$


Dividing both sides of (15) by $N_{t}$, taking growth rates of the resulting expression (in a discrete mathematical framework), and using (18) gives for the post-Malthusian balanced growth path

$$
\hat{m}^{* *}=\left(\hat{L}_{X}^{* *}+1\right)^{\frac{1}{\varepsilon-1}}-1 .
$$

Substituting (19) in (20) and substituting the resulting expression in (21) yields

$$
\hat{m}^{* *}=\left(\hat{\Omega}_{A}+1\right)^{\frac{1 /(\varepsilon-1)}{1-\gamma}}-1>0 \text { and } \partial \hat{m}^{* *} / \partial \hat{\Omega}_{A}>0 .
$$

Eq. (19) and eq. (22) imply: $\log \left(\hat{N}^{* *}+1\right)=\left(\frac{1}{1-\gamma}\right) \log \left(\hat{\Omega}_{A}+1\right)$ and $\log \left(\hat{m}^{* *}+1\right)=\left[\frac{1 /(\varepsilon-1)}{1-\gamma}\right] \log \left(\hat{\Omega}_{A}+1\right)$. Since we can approximate $\log (z+1) \approx z$ for any variable $\mathrm{z}$ that is significantly smaller than one, this implies the following relations:

$$
\begin{gathered}
\hat{N}^{* *} \approx\left(\frac{1}{1-\gamma}\right) \hat{\Omega}_{A}, \\
\hat{m}^{* *} \approx\left[\frac{1 /(\varepsilon-1)}{1-\gamma}\right] \hat{\Omega}_{A} .
\end{gathered}
$$

Since in (5) we assumed $\gamma<1$, it follows $\left(\frac{1}{1-\gamma}\right)>1$ and, therefore, (23) implies that an increase in $\hat{\Omega}_{A}$ leads to a more than proportional increase in $\hat{N}^{* *}$. In addition, it follows from (24) that an increase in $\hat{\Omega}_{A}$ leads to a more than proportional increase in $\hat{m}^{* *}$, provided $\left[\frac{1 /(\varepsilon-1)}{1-\gamma}\right]>1$.

COROLLARY 2: Theorem 2 implies that an exogenous increase in the growth rate $\hat{\Omega}_{A}$ has a positive effect on the post-Malthusiuan balanced growth rates of $N_{t}$ and $m_{t}$. For this reason, this growth change causes a permanent acceleration of population growth and per capita manufacturing output growth. 
Due to the assumption that each household inelastically demands $\tilde{a}$ units of the agricultural good, per capita agricultural production growth is, of course, always zero in our model. Hence, the result in Corollary 2 that an increase in $\hat{\Omega}_{A}$ causes an increase in $\hat{m}^{* *}$ implies that an increase in $\hat{\Omega}_{A}$ also causes an increase in the post-Malthusian balanced growth rate of per capita income. $^{22}$ Hence, recapitulating stylized fact (i) from Table 1 in section 2 , our model is able to replicate this stylized fact of the British industrial revolution. ${ }^{23}$ Put into the context of our model, we argue that Corollary 2 explains the transition from a Malthusian regime (i.e., the time before the British industrial revolution) to a post-Malthusian regime (i.e., the time after the British industrial revolution).

Moreover, the presence of a multiplier effect of $\hat{\Omega}_{A}$ on $\hat{N}^{* *}$ and $\hat{m}^{* *}$ was the most important element in the stylized facts (ii) and (iii) of Table 1. As was explained in section 2, the presence of these two multiplier effects is required for the increase in per capita income growth after the British industrial revolution to have been due entirely to an increase in per capita manufacturing output growth. Since Theorem 2 (ii) states that such multiplier effects are present, our model is able to replicate this dominant role of per capita manufacturing output growth in the British industrial revolution.

Theorem 2 (ii) states that the presence of a multiplier effect of $\hat{\Omega}_{A}$ on $\hat{m}^{* *}$ requires that particular parameter constellations are fulfilled. As can be seen from $(24)$, the presence of this multiplier effect requires that $\left[\frac{1 /(\varepsilon-1)}{1-\gamma}\right]>1$. In turn, this implies that our model only has a multiplier effect on $\hat{m}^{* *}$ if $1 /(\varepsilon-1)$ is sufficiently large. However, it can be seen from $(13)$, that $1 /(\varepsilon-1)$ is indeed sufficiently large, if the productivity gain in manufacturing good production from diversity of intermediate good varieties is sufficiently large, or in other words, if the effect of population growth on manufacturing pro-

\footnotetext{
${ }^{22}$ More specific, we mean the growth rate of per capita income deflated by a cost-ofliving index. In Appendix $\mathrm{C}$ we derive the fact that an increase in $\hat{\Omega}_{A}$ causes an increase in the post-Malthusian balanced growth rate of per capita income deflated by a cost-of-living index.

${ }^{23}$ Due to the constancy of per capita agricultural output, we fail to replicate one element in stylized fact (i), namely, the fact that per capita agricultural production growth fell after the British industrial revolution. However, we believe that the replication of the reduction of agricultural production growth is not of central importance to our argument: Moreover, it would unnecessarily have made our model more complicated. What is much more important is to replicate an increase in per capita income growth that is due entirely to per capita manufacturing output growth. As the following discussion of the implications of Theorem 2 (ii) shows, our model is able to replicate this latter feature.
} 


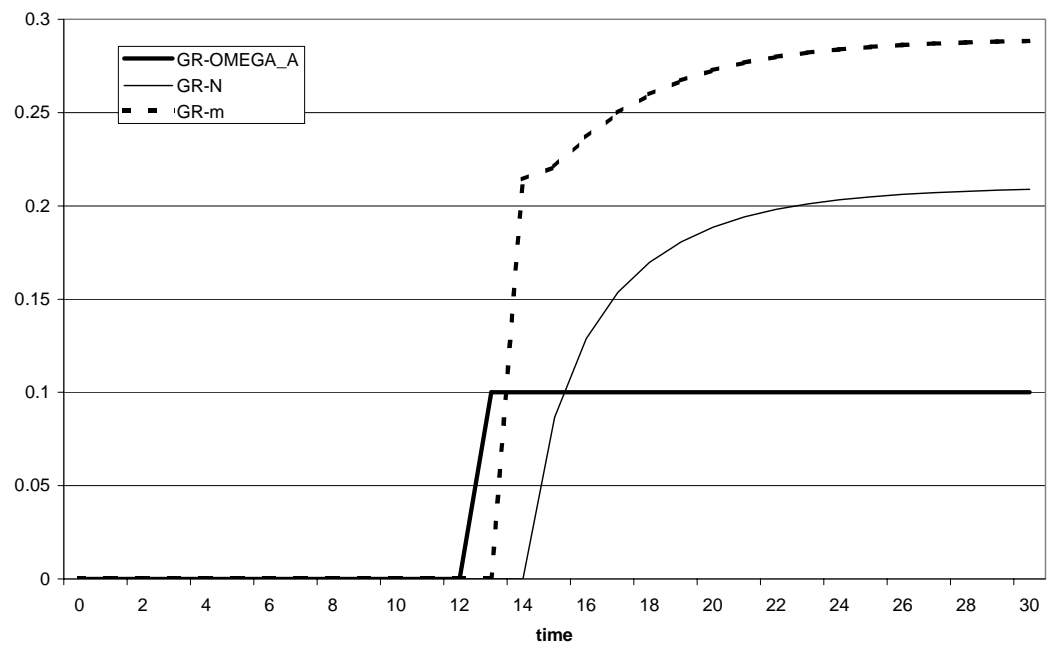

Figure 1: Transition from Malthusian steady state to postMalthusian balanced growth path. (In the simulation we set the parameter values at $\tilde{a}=0.1, \alpha=0.6, \beta=0.4, \gamma=0.5$, and $\varepsilon=1.75$. The initial size of population $N_{0}$ is set at the Malthusian steady state value of $N$. Furthermore, we assumed $\hat{\Omega}_{A, t}=0, \forall t=0, \ldots, 12$ and $\hat{\Omega}_{A, t}=0.1, \forall t=13, \ldots, T$, with $\mathrm{T}=30)$.

ductivity growth is sufficiently noticeable. As a consequence, population growth must have a sufficiently noticeable effect on manufacturing productivity growth for there to be a multiplier effect and, therefore, to enable our model to replicate the stylized facts of the British industrial revolution.

Figure 1 illustrates the way our model can explain the transition from the Malthusian steady state to the post-Malthusian balanced growth path. The solid bold line plots the exogenous time path of agricultural TFP, the solid thin line population growth and the dotted line per capita manufacturing output growth. Figure 1 illustrates that an exogenous increase in agricultural TFP growth causes an increase in population growth and per capita manufacturing output growth (and that those growth rates approach constant, positive equilibrium values as the economy reaches the post-Malthusian balanced growth path). In addition, the time paths in Figure 1 illustrate the presence of multiplier effects. This can be seen from the fact that the growth rates of agricultural TFP, population and per capita manufacturing output 
are all zero in the Malthusian steady state, while in the post-Malthusian balanced growth path the values of the growth rates of the population and of per capita manufacturing output exceed the growth rate of agricultural TFP. (As was explained earlier, for a multiplier effect on $\hat{m}^{* *}$ to be present, particular parameter constellations need to be fulfilled. For the specific simulation in Figure 1 the parameter values were chosen such that this was the case).

\section{A unified setting}

Since the focus of our paper is on the escape from the Malthusian trap as it is compatible with the stylized facts of the British industrial revolution we refrained from modeling the demographic transition in the previous section. However, as emphasized in the most recent literature, the challenge of economic growth theory is to model the escape from the Malthusian trap and the subsequent demographic transition in a unified setting. As we illustrate in this section, our model can be extended to also explain the demographic transition that followed the escape from the Malthusian trap.

In the previous section we assumed households to have a utility function with an elasticity of substitution between the manufacturing good and births of one. This assumption essentially simplified the model since it ensured that growth of agricultural TFP unambiguously leads to a take-off in population growth. However this assumption has the drawback that it prevents the emergence of a demographic transition, i.e., a situation where fertility may decline with increasing economic development. To facilitate the demographic transition we need to postulate a more general utility function (e.g., a CES type utility function) that allows for an elasticity of substitution between births and manufacturing good greater than one. Similar to Jones (1999a) we postulate a "lower bound" on fertility equal to $\tilde{b}$ which stands for the longrun rate of fertility. Each household still demands $\tilde{a}$ units of the agricultural good inelastically. Hence, each household's optimization problem is now ${ }^{24}$

$$
\max u_{t}=\left[m_{t}^{\frac{\sigma-1}{\sigma}}+\left(b_{t}-\tilde{b}\right)^{\frac{\sigma-1}{\sigma}}\right]^{\frac{\sigma}{\sigma-1}}, \text { with } \sigma>1,
$$

\footnotetext{
${ }^{24}$ Our utility function is similar to the utility function in Jones (1999a). While there is substitution between the economy's one good and the number of births in Jones' set up, our model assumes substitution between the manufacturing good and births with additional inelastic demand for an agricultural good.
} 


$$
\begin{array}{r}
\text { s.t. } a_{t}+p_{M, t} m_{t}+w_{t} \beta b_{t}=w_{t}, \\
a_{t} \geq \tilde{a}, m_{t} \geq 0, b_{t} \geq 0 .
\end{array}
$$

Upon use of the Karush-Kuhn-Tucker conditions this optimization problem gives rise to

$$
\frac{b_{t}}{m_{t}}=\frac{\left(w_{t} \beta\right)^{-\sigma}\left(w_{t}-\tilde{a}\right)+\left(p_{M, t}\right)^{1-\sigma} \tilde{b}}{\left(p_{M, t}\right)^{-\sigma}\left(w_{t}-\tilde{a}\right)-\left(w_{t} \beta\right)\left(p_{M, t}\right)^{-\sigma} \tilde{b}} .
$$

The production side of the economy is the same as in the previous section.

Growth of agricultural TFP has now two offsetting effects on the optimal number of births. On the one hand, it ensures that a smaller fraction of real wage income (i.e., nominal wage income deflated by a cost-of-living index as in Appendix C) must be devoted to the agricultural good, so that each household can afford more children. On the other hand, growth of agricultural TFP leads to a falling price for the manufacturing good for a given wage by boosting population growth and, therefore, boosting the rate of increase in productivity in the manufacturing sector. In turn, a falling price of the manufacturing good for a given wage leads to rising relative opportunity costs of births $\left(w_{t} \beta / p_{M, t}\right)$. Since $\sigma>1$, this leads, ceteris paribus, to a decline in births (through a substitution of a certain number of units of the manufacturing good for a certain number of units time devoted to births). For low levels of agricultural TFP, the positive effect of growth of agricultural TFP on the number of births dominates. However, once the level of agricultural TFP passes a certain threshold level, growth of agricultural TFP leads to a fertility decline, i.e., leads to the demographic transition.

An analytical solution of this model lies outside the scope of this paper. However the mechanism of the model becomes clear in the simulation results presented in Figure 2. ${ }^{25}$

Similar to Figure 1, an exogenous increase in agricultural TFP growth causes an increase in population growth and per capita manufacturing output growth with the presence of a multiplier effect up to about $t=40$. Further

\footnotetext{
${ }^{25}$ In order to get numerical results we make the simplifying assumption $\varepsilon=2 \sigma-1$. Under this condition we can analytically solve for the number of workers devoted to the manufacturing good sector $L_{X, t}$.
} 


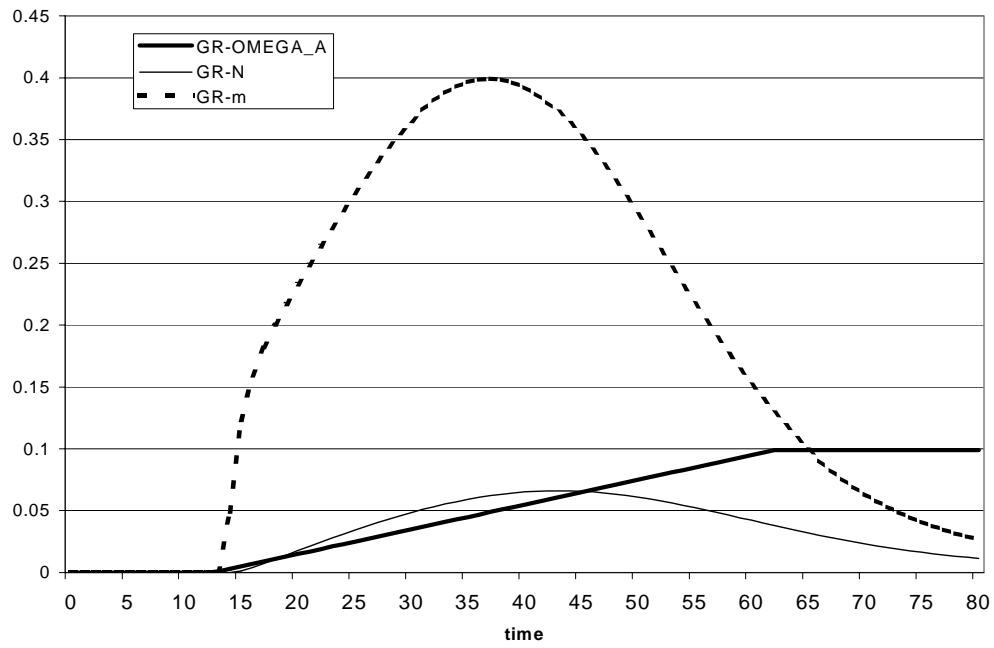

Figure 2: Transition from Malthusian steady state to modern growth regime and the demographic transition. (In the simulation we set the parameter values at $\tilde{a}=0.1, \beta=0.4, \gamma=0.5, \tilde{b}=0.85, \sigma=1.25$, $\delta=5, F=5$ and $\varepsilon=1.5$. The initial size of population $N_{0}$ is set at the Malthusian steady state value of $N$. Furthermore, we assumed that $\hat{\Omega}_{A, t}=0$, $\forall t=0, \ldots, 12$. The population size then linearly increases from 0.001 up to 0.1 between $t=13, \ldots, 63$, and is constant thereafter). 
growth of agricultural TFP beyond time $t=40$, however, leads to a fall in the number of births and consequently a slow down in population growth and per capita manufacturing output growth.

\section{Conclusion}

The paper aims to explain the industrialized world's escape from a regime with low economic growth and population growth (which we label the Malthusian regime) towards a regime with high economic growth and population growth (which we label the post-Malthusian regime). The paper introduces into a two-sector growth model demand factors that lead to industrialization and, in addition, it introduces endogenous fertility, i.e., we assume fertility to be the outcome of utility maximizing behavior. The results of our paper are twofold:

First, our model challenges the result of a two-sector growth model with constant population level in Matsuyama (1992, Section 2). In Matsuyama's model an exogenous increase in the level of agricultural TFP leads, due to rising demand for the manufacturing good, unambiguously to an acceleration of economic growth. Our paper shows that presence of endogenous population growth in Matsuyama's framework prevents the level of agricultural TFP productivity from having any long-run effect on economic growth. This is due to the fact that the increase in the agricultural TFP level has (due to a temporary wage increase) a temporary, positive effect on population growth (i.e., the demand for children rises). Because of decreasing returns to labor in agricultural good production, temporary population growth prevents the level of agricultural TFP from having any long-run impact on economic growth. In the present framework an increase in the growth rate of agricultural TFP increases the rate of economic growth.

Second, our model is able to replicate the stylized facts that can be inferred from data on the British industrial revolution. These data show a take-off in per capita income growth after the industrial revolution. Furthermore, a closer look at the data reveals that this take-off was entirely due to an increase in per capita manufacturing output growth. In contrast, the pre-industrial Malthusian trap and the feature that accelerating population growth after the industrial revolution caused per capita agricultural production growth to fall can only be explained with decreasing returns to labor in agricultural production. This means that only a two-sector model is capable 
of matching the data. We model technological progress in the manufacturing sector as an endogenous variable. As is argued in the recent literature in endogenous growth theory, this rate of technological progress increases in the rate of population growth. For this reason, population growth causes manufacturing productivity growth to accelerate. We demonstrate in the paper that, in case the effect of population growth on manufacturing productivity growth is sufficiently large, an increase in agricultural TFP growth has a multiplier effect on per capita manufacturing output growth, i.e., it leads to a more than proportional increase in per capita manufacturing output growth. In addition, our model implies the presence of a multiplier effect of an increase in agricultural TFP growth on population growth. That is, an increase in agricultural total factor productivity growth causes a more than proportional increase in population growth. Presence of these two multiplier effects enables our model to match the stylized facts of the British industrial revolution.

Additionally to these two main results, our proposed model framework maybe generalized to also replicate the modern growth regime as initiated by the demographic transition.

In the analytical part of the paper we have focused attention on long-run equilibria, which are (by definition) characterized as situations with constant employment shares of the two sectors. Clearly, empirical evidence shows that employment shares are time-varying when per capita income rises. This is exactly what happens in our models in the transitional phase towards the post-Malthusian balanced growth path and during the demographic transition. Nevertheless, we believe that the balanced growth path is a valid benchmark case (Matsuyama, 1992, uses a similar strategy and postpones an examination of time-varying employment shares to the Appendix).

\section{References}

[1] Aghion, P, Howitt, P., 1998. Endogenous Growth Theory, MIT Press, Cambridge MA.

[2] Bailey, R.E., Chambers, M.J., 1993. Long-term demographic interactions in precensus England. Journal of the Royal Statistical Society (Series A) 156, 339-362. 
[3] Baumol, W.J., 1967. Macroeconomics of unbalanced growth: the anatomy of urban crisis. American Economic Review 57, 415-426.

[4] Birdsall, N., 1983. Fertility and economic change in eighteenth and nineteenth century Europe: A comment. Population and Development Review 9, 111-123.

[5] Ciccone, A., 1997. Falling real wages during an industrial revolution. Unpublished working paper, University of Berkeley, CA.

[6] Coale, A., Treadway, R., 1986. A summary of the changing distribution of overall fertility, marital fertility, and the proportion married in the provinces of Europe. In: Coale, A., Watkins, S. (eds.), The Decline of Fertility in Europe, Princeton University Press, Princeton, NJ.

[7] Crafts, N.F.R., 1985. Income elasticities of demand and the release of labor by agriculture during the British industrial revolution: A further appraisal. In: Mokyr, J. (Ed.), The Economics of the Industrial Revolution. Rowman \& Allanheld, Totowa, NJ.

[8] Deaton, A.S., Muellbauer, J., 1980. Economics and Consumer Behavior. Cambridge University Press, Cambridge, UK and New York.

[9] Dyson., T., Murphy, M., 1985. The onset of fertility transition. Population and Development Review 11, 399-440.

[10] Edwards, B. K., Starr, R.M., 1987. A note on indivisibilities, specialization, and economies of scale. American Economic Review 77, 192-194.

[11] Ethier, W., 1982. National and international returns to scale in the modern theory of international trade. American Economic Review 72, 533-544.

[12] Galor, O., Weil, D.N., 1996. The gender gap, fertility, and growth. American Economic Review 86(3), 374-87.

[13] Galor, O., Weil, D.N., 1998. Population, technology, and growth: From the Malthusian regime to the demographic transition. Discussion Paper No. 1981, Centre for Economic Policy Research, London, September.

[14] Galor, O., Weil, D.N., 1999. From Malthusian stagnation to modern growth. American Economic Review 89, 150-154. 
[15] Goodfriend, M., Mc Dermott, J., 1995. Early development. American Economic Review 85, 116-133.

[16] Hansen, G. D., Prescott, E.C. , 1998. Malthus to Solow. Working Paper No. 6858, National Bureau of Economic Research, Cambridge, MA, December.

[17] Helpman, E., Krugman, P.R., 1985. Market Structure and Foreign Trade: Increasing Returns, Imperfect Competition, and the International Economy, MIT Press, Cambridge, MA.

[18] Kremer, M., 1993. Population growth and technological change: One million B.C. to 1990. Quarterly Journal of Economics, 108, 681-716.

[19] Jones, C.I., 1995a. Time series tests of endogenous growth models. Quarterly Journal of Economics 110, 495-525.

[20] Jones C.I., 1995b. R\&D-based models of economic growth. Journal of Political Economy 103, 759-784.

[21] Jones, C.I., 1999a. Was an industrial revolution inevitable? Economic growth over the very long run. Working Paper No. 7375, National Bureau of Economic Research, Cambridge, MA, October.

[22] Jones, C.I., 1999b. Growth: With or without scale effects?. American Economic Review 89, 139-144.

[23] Lee, R.D., 1997. Population dynamics: Equilibrium, disequilibrium, and consequences of fluctuations. In: Stark, O., Rosenzweig, M. (Eds), The Handbook of Population and Family Economics, Volume 1B. Elsevier, Amsterdam.

[24] Li, C.-W., 2000. Endogenous vs. semi-endogenous growth in a two-R\&Dsector model. Economic Journal 110, Issue 462, 109 - 122.

[25] Lucas, R.E., 1998. The Industrial Revolution: Past and Future. University of Chicago, Chicago, IL.

[26] Maddison, A, 1991. Dynamic Forces in Capitalist Development: A Long Run Comparative View. Oxford University Press, Oxford and New York.

[27] Malthus, T.R., 1798. An Essay on the Principle of Population. 
[28] Matsuyama, K., 1992. Agricultural productivity, comparative advantage, and economic growth. Journal of Economic Theory 58, 317-334.

[29] Nelson, R.R., 1956. A theory of the low level equilibrium trap in underdeveloped economies. American Economic Review 46, 894-908.

[30] Romer, P., 1990. Endogenous technological change. Journal of Political Economy 98 part 2, 71-102.

[31] Rostow, W.W., 1960. The Stages of Economic Growth: A NonCommunist Manufesto. Cambridge University Press, Cambridge, UK and New York.

[32] Segerstrom, P., 1998. Endogenous growth without scale effects. American Economic Review 88, 1290-1310.

[33] Steinmann, G., Prskawetz, A., Feichtinger, G., 1998. A model on the escape from the Malthusian trap. Journal of Population Economics 11, 535-550.

[34] Wrigley E.A., Schofield, R.S., 1981. The Population History of England 1541-1871, A Reconstruction. Harvard University Press, Cambridge, MA.

[35] Young, A, 1998. Growth without scale effects. Journal of Political Economy 106, 41-63.

\section{Appendix A: Proof of the Proposition}

ad (i):

Combining $N_{t}=b_{t-1} N_{t-1}$ with (7) yields after some manipulations

$$
\hat{w}_{t} \equiv \frac{w_{t}-w_{t-1}}{w_{t-1}}=b_{t-1}^{\frac{\gamma-1}{\gamma}}\left(\hat{\Omega}_{A}+1\right)^{\frac{1}{\gamma}}-1
$$

Suppose we have in the (Malthusian) steady state or (post-Malthusian) balanced growth path $\hat{w}_{t}=0$ (it will be shown in the proof of Proposition 1 (ii) that this situation is stable). In this case, (26) implies for this situation 


$$
b=\left(\hat{\Omega}_{A}+1\right)^{\frac{1}{1-\gamma}} .
$$

Clearly, since $\hat{N}=b-1$, this implies that we have

$$
\hat{N}=\left(\hat{\Omega}_{A}+1\right)^{\frac{1}{1-\gamma}}-1=\text { const } .
$$

Substituting (27) into (4) for b and rewriting yields

$$
w=\tilde{a} /\left[1-\left(\frac{\beta}{\alpha}\right)\left(\hat{\Omega}_{A}+1\right)^{\frac{1}{1-\gamma}}\right]=\text { const } .
$$

Zero profits for final manufacturing goods firms implies $p_{M, t} M_{t}=p_{X, t} X_{t}$, where $X_{t}$ denotes aggregate intermediate good output. Moreover, zero profits for intermediate goods firms imply $p_{X, t} X_{t}=w_{t} L_{X, t}$. Combining both zeroprofit conditions yields

$$
L_{X, t}=\left(\frac{p_{M, t}}{w_{t}}\right) M_{t} .
$$

Multiplying both sides of (3) with $N_{t}$, substituting the resulting expression in (30) for $M_{t}$ and collecting terms gives $\frac{L_{X, t}}{N_{t}}=(1-\alpha)\left(1-\frac{\tilde{a}}{w_{t}}\right)$. Since (29) $w=$ const. according to (29), we therefore get

$$
\frac{L_{X}}{N}=\text { const }
$$

ad (ii):

To determine the stability of the stationary value of the wage rate we rewrite (26) to obtain

$$
w_{t}=b_{t-1}^{\frac{\gamma-1}{\gamma}}\left(\hat{\Omega}_{A}+1\right)^{\frac{1}{\gamma}} w_{t-1} .
$$

Total differentiation of (32) w.r.t $w_{t-1}$ yields 


$$
\frac{d w_{t}}{d w_{t-1}}=b_{t-1}^{\frac{\gamma-1}{\gamma}}\left(\hat{\Omega}_{A}+1\right)^{\frac{1}{\gamma}}\left[1+w_{t-1}\left(\frac{\gamma-1}{\gamma}\right) b_{t-1}^{-1}\left(\frac{d b_{t-1}}{d w_{t-1}}\right)\right] .
$$

Upon differentiation of (4) w.r.t $w_{t-1}$, substituting the resulting expression together with (27) in (33), and substituting (29) in the resulting expression we get

$$
\left.\frac{d w_{t}}{d w_{t-1}}\right|_{w^{e q u i l i b r i u m}}=\left(\frac{1}{\gamma}\right)-\left(\frac{\alpha}{\beta}\right)\left(\frac{1-\gamma}{\gamma}\right)\left(\hat{\Omega}_{A}+1\right)^{\frac{-1}{1-\gamma}}
$$

The stationary state of $w_{t}$ is stable if $-1 \leq\left(d w_{t} / d w_{t-1}\right) \leq 1$. As can be verified from rearranging, the latter condition is fulfilled if $\left(\frac{\beta}{\alpha}\right)\left(\frac{1+\gamma}{1-\gamma}\right) \geq\left(\hat{\Omega}_{A}+\right.$ $1)^{\frac{-1}{1-\gamma}} \geq\left(\frac{\beta}{\alpha}\right)$. In turn, since according to $(27)$ in the steady state or balanced growth path $b=\left(\hat{\Omega}_{A}+1\right)^{\frac{1}{1-\gamma}}$, a glance at $(4)$ makes clear that $\left(\hat{\Omega}_{A}+1\right)^{\frac{1}{1-\gamma}} \leq$ $\left(\frac{\alpha}{\beta}\right)$ is always fulfilled. As a consequence, there is always fulfillment of $\left(\hat{\Omega}_{A}+\right.$ $1)^{\frac{-1}{1-\gamma}} \geq\left(\frac{\beta}{\alpha}\right)$. Hence, the stationary state of $w$ is stable, provided $\left(\hat{\Omega}_{A}+1\right)^{\frac{-1}{1-\gamma}} \leq$ $\left(\frac{\beta}{\alpha}\right)\left(\frac{1+\gamma}{1-\gamma}\right)$. However, fullfilment of the latter is ensured by Assumption 2 (ii).

\section{Appendix B: Proof that Assumption 2 guaranties $a_{t} \geq \tilde{a}, \forall t$}

Monotonic convergence of $w_{t}$ towards its equilibrium value is fullfiled if $0 \leq\left(d w_{t} / d w_{t-1}\right) \leq 1$. Rearranging (33) shows that fullfilment of this condition, and hence monotonic convergence of $w_{t}$, is guaranteed by fullfilment of $\left(\frac{\beta}{\alpha}\right)\left(\hat{\Omega}_{A, t}+1\right)^{\frac{1}{1-\gamma}} \geq 1-\gamma$, i.e., the inequality on the left-hand side of Assumption 2 (ii).

Moreover, let us denote $w^{e q}$ as the wage rate in the Malthusian steady state or the post-Malthusian balanced growth path. Then:

(i) Suppose $w_{0}<w^{e q}$, then monotony of $w_{t}$ ensures $w_{t} \geq \tilde{a}, \forall t$ and, therefore, $a_{t} \geq \tilde{a}, \forall t$ if $w_{0} \geq \tilde{a}$. The latter was ensured with Assumption 2 (i).

(ii) Suppose $w_{0}>w^{e q}$, then monotony of $w_{t}$ ensures $w_{t} \geq \tilde{a}, \forall t$ and, therefore, $a_{t} \geq \tilde{a}, \forall t$ if $w^{e q} \geq \tilde{a}$. However, as a glance at (29) reveals, the latter is fulfilled with fulfillment of the inequality on the right-hand side of Assumption 2 (ii). 


\section{Appendix C: Derivation that $\partial\left({\widehat{y^{*}}}_{p_{c}^{* *}}\right) / \partial \hat{\Omega}_{A}>0$}

For nominal per capita income $y^{n}$ it follows from our model

$$
y_{t}^{n}=w_{t}\left(1-\beta b_{t}\right) .
$$

Following the literature in applied economics we approximate the true costof-living index by Stone's price index [see Deaton and Muellbauer (1980)], which is

$$
p_{c, t}=(1)^{\mu}\left(p_{M, t}\right)^{1-\mu},
$$

where the price of the agricultural good is normalized to one and $\mu$ denotes the budget share of the agricultural good in total expenditures. In this approximation the budget shares are assumed to be constant (and are either the average budget shares for the time period of our investigation or are evaluated at a particular base year). Since according to (29) and (27) $w_{t}$ and $b_{t}$ are constant in the post-Malthusian balanced growth path, it can be seen from (35) that in this situation $y_{t}^{n}$ is also constant. Therefore, it is straightforward to derive for the per capita income deflated by a cost-of-living index

$$
\frac{{\widehat{y^{n}}}^{* *}}{p_{c}}=-\left(\frac{\hat{p}_{c}}{\hat{p}_{c}+1}\right) .
$$

Substitution of (11) in (9) yields

$$
p_{M, t}=Q_{t}^{\frac{1}{1-\varepsilon}}\left(\frac{\varepsilon}{\varepsilon-1}\right) w_{t} \delta .
$$

Substituting (38) in (36), taking growth rates of the resulting expression, and using the fact that according to (29) in the post-Malthusian balanced growth path $\mathrm{w}=$ const., we get

$$
\hat{p}_{c}^{* *}=\left(\hat{Q}^{* *}+1\right)^{\frac{1-\mu}{1-\varepsilon}}-1 .
$$

Taking growth rates of (14) and substituting (20) in the resulting expression yields

$$
\hat{Q}^{* *}=\hat{N}^{* *}
$$


Eq. (39) implies $\log \left(\hat{p}_{c}^{* *}+1\right)=\left(\frac{1-\mu}{1-\varepsilon}\right) \log \left(\hat{Q}^{* *}+1\right)$. Since for any variable $\mathrm{z}$ that is significantly smaller than one we can approximate $\log (z+1) \approx z$, it follows that

$$
\hat{p}_{c}^{* *} \approx\left(\frac{1-\mu}{1-\varepsilon}\right) \hat{Q}^{* *} .
$$

Substitutioning of (23) in (40) and substituting the resulting expression in (41), we obtain $\hat{p}_{c}^{* *} \approx\left[\frac{1-\mu}{(1-\gamma)(1-\varepsilon)}\right] \hat{\Omega}_{A}$. Substituting the latter relation in (37) gives rise to

$$
\frac{{\widehat{y^{n}}}^{* *}}{p_{c}} \approx-\left(\frac{\left[\frac{1-\mu}{(1-\gamma)(1-\varepsilon)}\right] \hat{\Omega}_{A}}{\left[\frac{1-\mu}{(1-\gamma)(1-\varepsilon)}\right] \hat{\Omega}_{A}+1}\right) .
$$

Differentiating (42) w.r.t $\hat{\Omega}_{A}$ and recapitulating that $\varepsilon>1$, it can be verified that

$$
\partial\left({\frac{y^{n}}{p_{c}}}^{* *}\right) / \partial \hat{\Omega}_{A}>0
$$

